【研究简报】

\title{
黔西南金锑矿床成矿流体中 轻烃物质的初步研究
}

\author{
庄汉平 (1) 卢家烂 (1) 傅家谟 (1) 刘金钟 (1) 施继锡 (2) \\ (1)中国科学院广州地球化学研究所, 广州 510640; (2)中国科学院地球化学研究所, 费阳 550002)
}

\section{关键词駖西南 金锑矿床 轻烃物质}

成矿流体是金属元素沉淀的直接介质, 成矿流体中的有机物质是研究有机质在金属成矿 中的作用的最直接窗口之一 ${ }^{[1]}$. 由于许多矿床成矿温度均已超过液态烃稳定存在的温度范 围, 在流体包裹体中仅存轻烃物质 ${ }^{1)}$. 因此, 轻烃物质就成为判识成矿流体中有机质的最直接 标志之一. 本文选择了黔西南有代表性的金锑矿床 (烂泥沟金矿床和大厂钩矿床), 实验研究 了矿物包裹体中的轻烃物质.

\section{1 样品与方法}

烂泥沟金矿床石英脉采自磺厂沟剖面, 石英脉宽 $2 \sim 20 \mathrm{~mm}$, 网脉状或雁行脉状, 为晚期 矿化石英脉. 从石英脉中挑选出较纯的乳白色石英作为分析样品, 并作流体包裹体观测. 石 英中的流体包裹体基本上为单期原生包裹体, 以气液两相包裹体为主, 气液比 $<10 \%$; 也可见 气态包裹体, 但数量较少 $(<10 \%)$. 包裹体均匀分布, 均一温度 $170 \sim 230^{\circ} \mathrm{C}$, 平均 $205^{\circ} \mathrm{C}$.

大厂铎矿萤石采自锑矿体, 萤石呈淡绿色, 四面体晶型较好, 解理发育, 晶面光滑平整. 黄 石中的包裹体由单期的气液两相包裹体组成, 亦为原生包裹体. 包裹体个体较大, $2 \sim 20 \mu \mathrm{m}$, 个别可达 $30 \mu \mathrm{m}$, 气液比 $5 \% \sim 30 \%$, 均一温度 $157 \sim 1755^{\circ} \mathrm{C}$, 平均约 $170{ }^{\circ} \mathrm{C}$.

烂泥沟金矿床和大厂锑矿床详细的地质地球化学特征参见文献 [2]和 [3].

从原矿石中尽可能地挑选纯的石英或茧石, 在不锈钢研针中轻轻砸碎, 然后在玻璃板上挑

4 Albaiges J, Algaba J, Grimalt J, et al. Extractable and bound neutral lipids in some lacustrine sediments. In: Schenck P A, de Leeuw J W, Lijmbach G W M eds. Advances in Organic Geochmistry 1983, Oxford: Pergamon, 1984.223 236

5 Eglinton G, Hunneman D H. Gas chromatographic-mass spectrometric studies of long chain hydroxy acids- I : the constituent cutin acids of apple cuticle. Phytochemistry, 1968,7:313 322

6 Eglinton G, Hunneman D H, Douraghi-Zaden K. Gas chromatographic-mass spectrometric studies of long chain hydroxy acidsII : the hydroxy acids and fatty acids of a 5 000-year-old lacustrine sediment. Tetrahedron, 1968,24:5 929 5941

7 Schenck P A. 作为沉环境指标的生物标志物. 中国科学院地球化学研究所有机地球化学开放实验室年报 (1986), 费 阳: 贵州人民出版社, 1987. 172 182

8 Eyssen $\mathrm{H} \mathrm{J}$, Parmentier G G, Compernolle F C, et al. Biohydrogenation of sterols by Eubacterium ATCC 21-408, Nova species. Eur J Biochem, 1973, 36:411 421 
选直径在约 $1 \mathrm{~mm}$ 的、没有粘连其它矿物质的石英或茧石, 再从初步挑选的石英或茧石中精选 出表面光滑平整、无裂纹和无粘附物的矿物颗粒. 经过三次挑选之后, 样品基本上由纯净的石 英或薥石组成. 将物理纯化后的石英和茧石在烧杯中用无水乙醇轻轻淘洗, 倒出无水乙醇后 用 $\mathrm{CHCl}_{3}$ 冲洗, 如此反复多次除去矿物表面粘附的微粒和粉尘. 然后, 用 $\mathrm{CHCl}_{3}$ 抽提, 得到表 面没有有机烃吸附的纯净石英和茧石.

将纯化的石英和茧石真空密封在硬质玻璃管中, 放入马弗炉中加热, 石英加热温度为 (350 $\pm 5)^{\circ} \mathrm{C}$, 茧石为 $(250 \pm 5)^{\circ} \mathrm{C} .6 \mathrm{~h}$ 后取出样品, 冷却后开启玻璃管收集气体, 测定气体产率, 并 作轻烃色谱分析. 轻烃分析在 HP5890 II 型气相色谱上完成.

\section{2 结果}

由于石英和茧石中不含有固体有机物质, 排除了热解烃加入的可能性, 从包裹体中释放出 来的轻烃基本保持了包裹体中原始烃类成分. 石英和萤石中的包裹体均为与矿化同期的单期 原生包裹体. 因此包裹体中的轻烃组成基本代表了成矿流体中的轻烃组成.

石英样重 $6.8762 \mathrm{~g}$, 产气 $8.86 \mathrm{~mL}$; 萤石样重 $5.9309 \mathrm{~g}$, 产气 $19.34 \mathrm{~mL}$. 薥石的产气率 是石英的 2.5 倍. 石英包裹体轻烃主要由甲烷组成 $(87.543 \%$, 体积百分数, 下同)(图 1 (a), 表 1), 其次为乙烷 (6.242\%), 丙烷 (2.495\%) 和丁烷 (1.173\%), 这四种烷烃就占了总量的 $97.453 \%$. 相对而言, 烯烃占极小一部分, $\mathrm{C}_{6}^{-}$烯 $/ \mathrm{C}_{6}^{-}$烷 $=0.009$ (表 1), 烯烃与相同碳数的烷 烃比值 $<0.2$, 表明烷烃占绝对优势. 此外, 还有一定数量的环烷烃, 环构化指数为 0.069 .

与石英相比, 黄石中的烯烃含量明显增加 (图 1(b)), 烯烃含量也基本接近烷烃含量, $\mathrm{C}_{6}^{-}$ 烯 $/ \mathrm{C}_{6}^{-}$烷 $=0.716 . \mathrm{C}_{2} \sim \mathrm{C}_{5}$ 烯烃比相应碳数的烷烃含量要高出许多倍, 如乙烯 $/$ 乙烷 $=$ 41.499. 鳋石的另一特征是缺少环烷烃, 环构化参数为 0 .
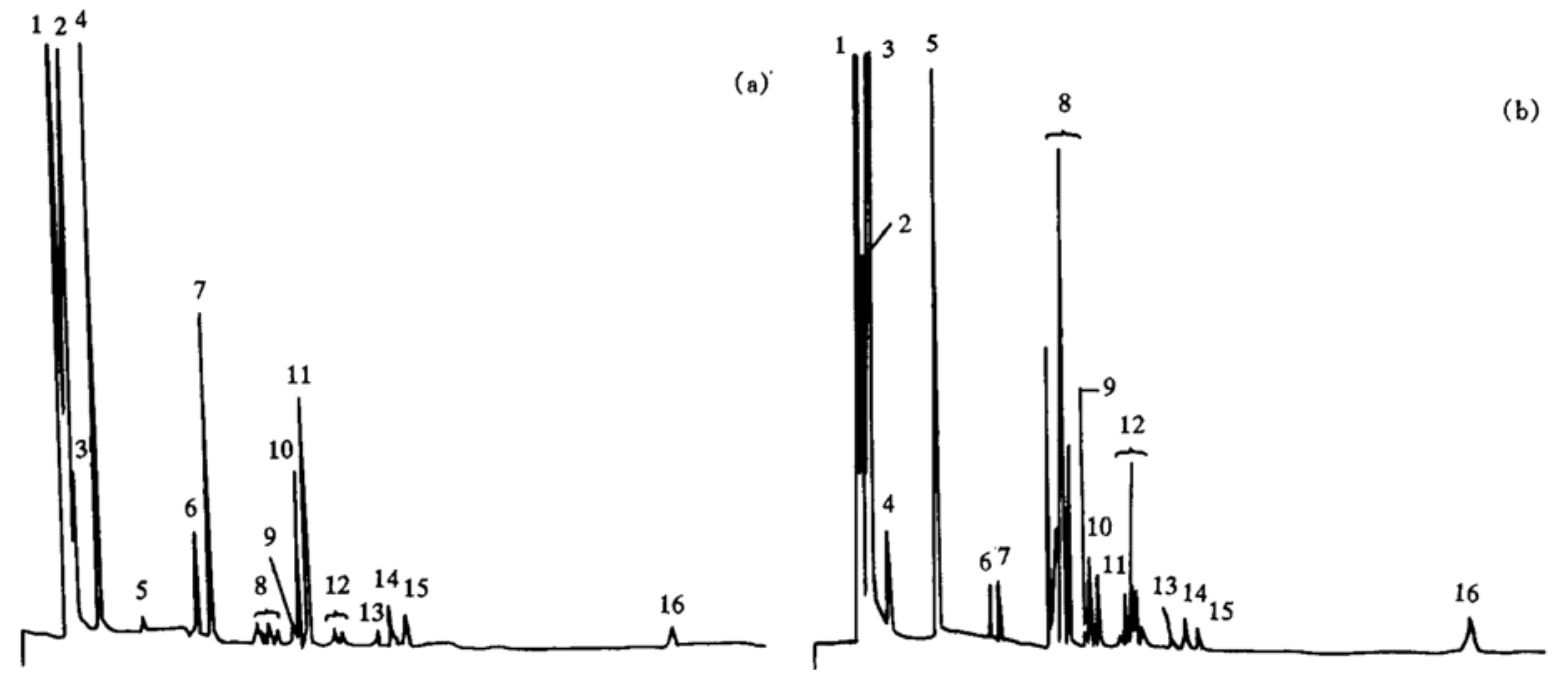

图 1 矿物包裹体中轻烃的气相色谱

（a）烂泥沟金矿床晚期石英脉; (b)大厂锑矿萤石

\section{3 讨论}

轻烃的组成是其母质类型和来源的反映, 具相似结构的正烷烃在演化过程中具有很好的 相关性; 对于相同来源正庚烷与正己烷, 它们的比值基本保持稳定 ${ }^{[4]}$. 因此, 可用其比值判识 
表 1 烂泥沟金矿床石英脉和大厂锑矿茧石流体包畺体中轻烃分析

\begin{tabular}{|c|c|c|c|c|c|c|c|}
\hline \multirow{2}{*}{ 峰号 } & \multirow{2}{*}{ 名称 } & \multirow{2}{*}{ 化学式 } & \multicolumn{2}{|c|}{ 占总有机气体体积的比例 $/ \%$} & \multicolumn{3}{|c|}{ 轻烃参数 } \\
\hline & & & 石英 & 茧石 & 参数 & 石英 & 董石 \\
\hline 1 & 甲烷 & $\mathrm{CH}_{4}$ & 87.543 & 56.218 & $i \mathrm{C}_{4} / n \mathrm{C}_{4}$ & 0.344 & 0.871 \\
\hline 2 & 乙㜔 & $\mathrm{C}_{2} \mathrm{H}_{6}$ & 6.242 & 0.877 & $i \mathrm{C}_{5} / n \mathrm{C}_{5}$ & 0.667 & 1.144 \\
\hline 3 & 乙烯 & $\mathrm{C}_{2} \mathrm{H}_{4}$ & 0.560 & 36.395 & $\mathrm{C}_{6}^{-}$烯/ $\mathrm{C}_{6}^{-}$烷 & 0.009 & 0.716 \\
\hline 4 & 间烷 & $\mathrm{C}_{3} \mathrm{H}_{8}$ & 2.495 & 0.326 & $\mathrm{C}_{2}$ 烯/ $\mathrm{C}_{2}$ 烷 & 0.090 & 41.499 \\
\hline 5 & 丙烯 & $\mathrm{C}_{3} \mathrm{H}_{6}$ & 0.079 & 2.496 & $\mathrm{C}_{3}$ 烯/ $\mathrm{C}_{3}$ 烷 & 0.032 & 7.656 \\
\hline 6 & 异丁烷 & $\mathrm{C}_{4} \mathrm{H}_{10}$ & 0.403 & 0.169 & $\mathrm{C}_{4}$ 烯/ $\mathrm{C}_{4}$ 烷 & 0.117 & 6.458 \\
\hline 7 & 正丁烷 & $\mathrm{C}_{4} \mathrm{H}_{10}$ & 1.173 & 0.174 & $\mathrm{C}_{5}$ 烯/ $\mathrm{C}_{5}$ 烷 & 0.061 & 2.134 \\
\hline 8 & 丁’烯 & $\mathrm{C}_{4} \mathrm{H}_{8}$ & $0.184^{a)}$ & $2.215^{\mathrm{c})}$ & 正构烷参数e) & 2.784 & 1.368 \\
\hline 9 & 环戊阭 & $\mathrm{C}_{5} \mathrm{H}_{10}$ & 0.026 & 0.000 & 环构化参数 ${ }^{n)}$ & 0.069 & 0.000 \\
\hline 10 & 异戊烷 & $\mathrm{C}_{5} \mathrm{H}_{12}$ & 0.350 & 0.135 & 正庚烷/正己焙 & 0.693 & 3.410 \\
\hline 11 & 正戊烷 & $\mathrm{C}_{5} \mathrm{H}_{12}$ & 0.525 & 0.118 & & & \\
\hline 12 & 戊烯 & $\mathrm{C}_{5} \mathrm{H}_{10}$ & $0.053^{\mathrm{b})}$ & $0.540^{\mathrm{d})}$ & & & \\
\hline 13 & 甲基环戊烷 & $\mathrm{C}_{6} \mathrm{H}_{12}$ & 0.035 & 0.000 & & & \\
\hline 14 & 异戊烯 & $\mathrm{C}_{6} \mathrm{H}_{14}$ & 0.140 & 0.090 & & & \\
\hline 15 & 正己烷 & $\mathrm{C}_{6} \mathrm{H}_{14}$ & 0.114 & 0.056 & & & \\
\hline 16 & 正庚烷 & $\mathrm{C}_{7} \mathrm{H}_{16}$ & 0.079 & 0.191 & & & \\
\hline
\end{tabular}

a) 4 个小峰总和; b) 2 个小峰总和; c) 4 个小峰总和; d) 5 个小峰总和; e) 正构化参数 $=\Sigma\left(n \mathrm{C}_{4} \sim n \mathrm{C}_{7}\right) / \Sigma\left(i \mathrm{C}_{4} \sim i \mathrm{C}_{7}\right)$; f) 环构化参数 $=\Sigma\left(c \mathrm{C}_{4} \sim c \mathrm{C}_{7}\right) / \Sigma\left(i \mathrm{C}_{4} \sim i \mathrm{C}_{4}\right)$

有机质来源. 石英的正庚烷/正已烷 $=0.69$, 而茧石为 3.41 , 两者相差很大, 表明它们具有明 显不同的有机质来源.

环戊烷、环已烷及其低分子量的同系物 $\left(<\mathrm{C}_{10}\right)$ 是原油的重要组分 ${ }^{[4]}$, 石英包裹烃环构化 参数为 0.069 , 而茧石中该参数为 0 , 表明石英包裹烃可能为石油来源, 而茧石包裹烃为非石油 来源. 石英烷烃 $\mathrm{C}_{1} / \mathrm{C}_{2}-\mathrm{C}_{1} / \mathrm{C}_{3}-\mathrm{C}_{1} / \mathrm{C}_{4}$ 比值投影介于原油和天然气之间, 茧石位于天然气之上 (图略), 表明石英中轻烃来源于腐泥-腐殖型成油母质, 而葷石中轻烃来源于腐殖型产气母质.

异构烷烃还可能指示成烃环境, 在成煤的酸性-弱酸性环境下, 轻烃的形成通常以碳阳离 子断裂 (异裂) 为主, 主要产物是异构烷烃, 即使在烃源岩进入高成熟阶段, 异构烷烃与相应碳 数的正构烷烃比值仍然趋于 1 , 甚至 $>1$. 萤石的 $i \mathrm{C}_{4} / n \mathrm{C}_{4}$ 和 $i \mathrm{C}_{5} / i \mathrm{C}_{5}$ 分别为 0.971 和 1.144, 可能表明瞢石烃来自含煤地层.

$i \mathrm{C}_{4} / n \mathrm{C}_{4}$ 和 $i \mathrm{C}_{5} / n \mathrm{C}_{5}$ 比值被认为是成熟度指标 ${ }^{[4]}$, 随有机质成熟度增加, 该比值降低. 由此可以推测石英包裹烃成熟度比茧石包裹烃成熟度高, 这与包裹体均一温度是一致的.

烯烃是一种不饱和烃, 其 $\mathrm{C}=\mathrm{C}$ 双键具很大的化学活性, $\mathrm{C}=\mathrm{C}$ 双键的键能是 $611 \mathrm{~kJ} / \mathrm{mol}$, 比一般的单键 $374 \mathrm{~kJ} / \mathrm{mol}$ 大得多. 因此, 在有催化剂的条件下很容易和 $\mathrm{H}_{2}$ 或卤化物通过加 氢反应生成烷烃和图代烃 ${ }^{[5]}$. 萤石中异常丰度的烯烃可能是煤系有机质近地表较温和的氧 化作用以及鳋石的封闭的保存条件共同作用的结果, 是煤系有机质参与硫酸盐近地表热化学 还原的产物.

总之, 矿物包裹烃的分析表明烂泥沟金矿床中石英包裹烃可能来源于原油, 具有较高的成 熟度. 大厂锑矿茧石包裹烃可能来源于煤系有机质, 具有相对较低的成熟度, 异常含量的烯烃 表明煤系有机质层参与过近地表环境下的硫酸盐热化学还原作用.

致谢本工作为国家“攀登”计划(PA30)资助项目. 


\title{
【研究简报】
}

\section{煤成油排驱主要制约因素}

\author{
赵长毅程克明
}

(石油勘探开发科学研究院地质研究所, 北京 100083)

\section{关键词煤成油 排驱 孔隙 表面化学}

煤成油的排驱是指煤在热成熟作用过程中, 生成的烃类物质在某种动力的驱动下从煤层 母体排出至输导层的过程. 煤所生烃类排出母体一方面取决于煤所具有的固有内在属性, 它 包括两个含义: 其一是煤原始生烃潜力, 它决定了煤中烃类达到含油饱和度的难易程度; 其二 是煤分子排列格架及分子质点表面性质, 它决定了烃类储存空间大小与烃类流动的难易程度. 另一方面, 外生地质营力的存在是煤层发生排烃作用的必要条件. 适当的构造挤压应力及存 在通过源岩的输导层 (如断裂、层理面、剥蚀面等) 以便形成差异应力, 为烃类排驱与运移提供 了外在条件, 这两方面缺一不可. 吐哈盆地煤成油的排驱亦正是煤内在属性与外部构造挤压 力共同作用的结果.

\section{1 烃类分子与煤孔隙表面质点相互作用机理与本质}

煤在热演化过程中, 其大分子由于内部键能的差异导致随热力学条件的变化而逐渐降解 脱落成小分子烃类. 脱落的小分子首先与有机固体颗粒表面相互作用, 被煤孔隙表面质点所 “捕捉”(图 1).

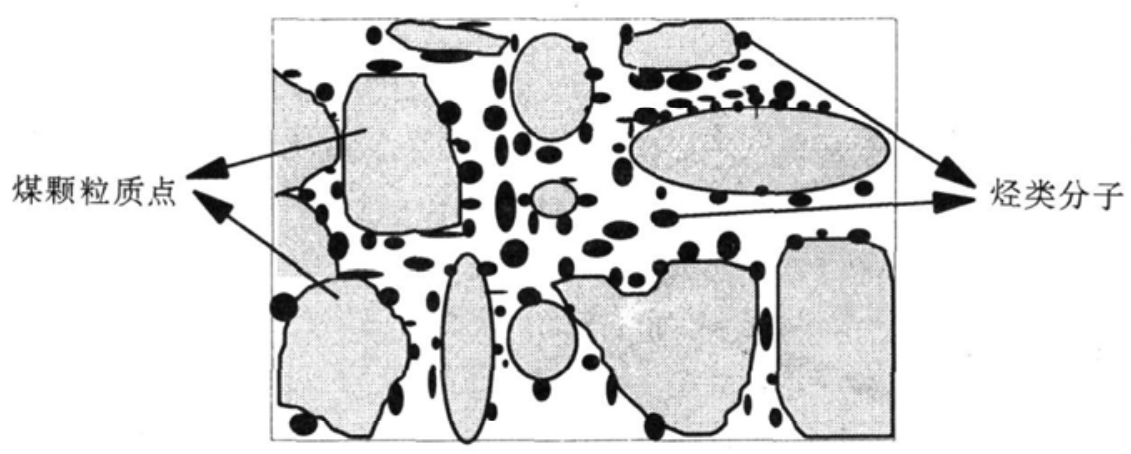

图 1 煤孔隙表面与烃类作用示意图

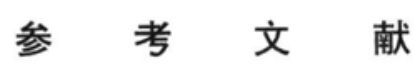

1 庄汉平, 卢家烂, 温汉捷, 等. 成矿流体中的有机物质. 地质地球化学, 1997, (1):85 91

2 罗孝恒. 贵州贞丰烂泥沟金矿床地质特征、成矿机理及找矿. 见: 刘东升主编. 中国卡林型(微细浸染型)金矿床, 南 京: 南京大学出版社, 1995. 79 99

3 叶造军. 有机质在晴隆大厂铇矿成矿中的作用. 地质地球化学, 1995, (6): 111 113

4 林壬子. 轻烃技术在油气勘探中的应用, 武汉: 中国地质大学出版社, 1992. 1 155

5 徐寿昌. 有机化学, 第二版. 北京: 高等教育出版社, 1993. 1 543 